\title{
Level of Alpha Amylase Activity in Human Saliva as Noninvasive Biochemical Marker of Sleep Deprivation
}

\author{
${ }^{1}$ Rohit K Pradhan, ${ }^{2} \mathrm{~N}$ Sinha
}

\begin{abstract}
Every section of our round-the-clock society is plagued with the problem of sleep deprivation. Genetic studies conducted on lower organism have revealed that the measurement of salivary alpha amylase (SAA) levels could be a useful noninvasive diagnostic tool for the assessment of sleepiness in human beings. But the reports at population level are still lacking. The present study was conducted longitudinally over a period of 2 years and was targeted upon the adolescent school-going students whose sleep requirements and obtained sleep duration differs widely due to school timings, assignments, and social activities. Totally, 168 healthy school-going adolescents studying in ninth grade were selected randomly from morning shift $(n=84)$ and dayshift $(n=84)$ schools. The study encompassed administration of questionnaire and collection of saliva samples from the participants. Salivary alpha amylase activity was estimated spectrophotometrically and statistical analysis was performed in order to determine its association with sleep duration and sleepiness level. Findings reveal that SAA could be the most appropriate noninvasive biochemical marker for the objective assessment of sleep deprivation among individuals as well as at population level.
\end{abstract}

Keywords: Adolescents, Excessive daytime sleepiness, Salivary alpha amylase, Sleep deprivation.

How to cite this article: Pradhan RK, Sinha N. Level of Alpha Amylase Activity in Human Saliva as Noninvasive Biochemical Marker of Sleep Deprivation. Indian Sleep Med 2017;12(2):1-6.

Source of support: Nil

Conflict of interest: None

\section{INTRODUCTION}

Sleep-related problems and susceptibility toward stress, the two most common features of the modern society, are interrelated. The scientific community has done considerable effort to establish a valid biomarker for the assessment of the sleepiness and stress level in human beings. In order to explore useful biomarkers, saliva is considered the most suitable medium due to ease of its collection and causing least discomfort to the subjects.

\footnotetext{
${ }^{1}$ Professor, ${ }^{2}$ Research Scholar

${ }^{1,2}$ School of Studies in Life Sciences, Pt. Ravishankar Shukla University, Raipur, Chhattisgarh, India

Corresponding Author: Rohit K Pradhan, Professor, School of Studies in Life Sciences, Pt. Ravishankar Shukla University Raipur, Chhattisgarh, India, e-mail: rkp299@gmail.com
}

One such biomarker, sAA, has been studied widely and recommended as a marker of activity of sympathetic nervous system. ${ }^{1-3}$ It has been suggested that the level of the enzyme alpha amylase increases in saliva in response to stressful conditions with an increase in the sympathetic nervous system activity. The sympathetic activity is also known to increase due to reduced duration of sleep. ${ }^{4}$ Increase in sAA activity has also been reported among individuals suffering from obstructive sleep apnea syndrome, which is a major cause of excessive daytime sleepiness (EDS) among such patients. ${ }^{5}$ Though genetic studies using drosophila as model organism have revealed a strong association between amylase messenger ribonucleic acid (mRNA) and sleep deprivation, ${ }^{6,7}$ the association between salivary amylase enzyme activity and sleep deprivation in human has not yet been studied extensively on a larger sample size.

Sleep need varies considerably across different age groups and the need for sleep is higher among adolescents as compared with prepubertal children, younger children, and adults. ${ }^{8,9}$ Adolescence is a stage between childhood and adulthood which is associated with behavioral and psychosocial changes. The sleep requirement of adolescents is more than that of adults or children because of their physiological requirement. However, the higher need for sleep in adolescents largely remains unmet due to a number of factors, such as school timing, increasing academic demand, and tendency to stay awake late at night. This sleep deprivation in adolescents is known to interfere with their capacity of learning and ability to sustain attention, ${ }^{10,11}$ which results in poor school performance, behavioral problems, ${ }^{12,13}$ and even road accidents. $^{14}$

The devastating effects of sleep deprivation have become important to address because not only adolescents but also adults experience EDS due to changing living style. ${ }^{15}$ Further, there are growing evidences suggesting that neurodegenerative disorders, such as Alzheimer's and Parkinson's disease are intrinsically associated with unhealthy sleep. ${ }^{16,17}$ However, a potent quantifiable noninvasive biochemical marker for objective assessment of sleep deprivation has not been established as yet. The present study carried out on a large schoolgoing adolescent population for two consecutive years is an attempt to find out not only the effect of school timings 
on adolescents sleep but also to validate the candidature of salivary amylase as a noninvasive biochemical marker for assessment of sleepiness level.

\section{MATERIALS AND METHODS}

Five different schools located in the urban area of Raipur (Chhattisgarh, India) were selected, out of which two schools had the start timing 7:30 AM (morning shift) and three schools had the start timing 11:00 AM (dayshift). Consent of the school authorities was obtained for conducting the present study. This study was funded by the Chhattisgarh Council of Science and Technology (CGCOST), Raipur (Grant No. 8043/CCOST/MRP/13, Raipur dated 27/12/2013). All procedures performed in studies involving human participants were in accordance with the ethical standards of the institutional research committee (IEC Ref No. 017/IEC/PRSU/2013 dated April 15, 2013) and with the 1964 Helsinki Declaration and its later amendments or comparable ethical standards. Informed consent was obtained from all individual participants included in the study. Administration of questionnaire and collection of saliva sample was carried out longitudinally for a period of two consecutive years. Students were studying in the ninth class when the present study was initiated and were followed up till the completion of their tenth class. The study was initiated in the academic session 2014 to 2015 and 168 students participated in the study in the first year. Eighty-four students were from morning shift schools (46 girls and 38 boys) and 84 students ( 28 girls and 56 boys) were from the dayshift schools. Some of the students could not be followed up in the second year due to migration to other schools or withdrawal from participation by some students. Hence, for the academic session 2015 to 2016, the total number of participants was 150; out of this, 79 were from morning shift schools (43 girls and 36 boys) and 71 from dayshift schools ( 25 girls and 46 boys). Twelve students in the first year and 10 students in the second year were eliminated from the study because of the incomplete biographical information. All the students enrolled in the present study were healthy, neither suffering from any kind of psychiatric illness and major diseases nor adhering to any kind of medication. The average age of students was $14.19 \pm 0.07$ and $14.25 \pm 0.08$ respectively, in morning and dayshift group.

Questionnaires were distributed directly to the participants in the leisure and completely filled-in questionnaires were collected back from them. Questionnaire included biographical information and sleep habits (bedtime and wakeup time) during weekdays and in the weekends, and their health status. Sleep duration of students was computed using self-reported bedtime and wake time.
The saliva samples for estimation of enzyme activity were collected from the students of either shift between 11:00 and 11:30 AM to eliminate any time effect. Saliva samples were collected from the students in their natural setting just 1 month prior to final examination (in the month of January). Samples were stored in a refrigerator at $-20^{\circ} \mathrm{C}$ and assayed for the enzyme alpha amylase within 1 month.

\section{SALIVARY AMYLASE ESSAY}

Activity of the salivary amylase was assessed by utilizing Agappe diagnostic kit. Samples were thawed and brought up to room temperature before performing the assay. Samples were centrifuged at 3,000 rpm for 15 minutes and diluted (1:400) with normal saline; $25 \mu \mathrm{L}$ of sample was taken out in the cuvette. To $25 \mu \mathrm{L}$ of diluted saliva sample, $1 \mathrm{~mL}$ of substrate (2-chloro-4-nitrophenyl$\alpha$-maltotrioside) provided in the assay kit was added and the mixture was incubated at $37^{\circ} \mathrm{C}$ for 1 minute. Change in absorbance per minute was measured at $405 \mathrm{~nm}$ for a period of 3 minutes. Amylase activity was calculated by using the formula:

$$
\begin{aligned}
\text { Alpha amylase activity }(\mathrm{U} / \mathrm{mL})= & {[(\mathrm{OD} / \mathrm{min}) \times 3,178 \times} \\
& 400] / 1,000
\end{aligned}
$$

\section{RESULTS}

Comparative account of sleep habits of school students as a function of school timing in the first and second year has been depicted in Tables 1 and 2 respectively. Table 3 summarizes the sleep behavior of morning as well as dayshift students in the first and second year of the study computed through paired t-test.

\section{Comparative Account of Sleep Habits of School Students as a Function of School Timing}

Analysis of variance (ANOVA) revealed a significant difference between sleep duration (in weekdays as well as weekends) and wakeup time of morning and dayshift school students for a period of two consecutive years. A significantly less sleep duration and earlier wakeup time was observed among morning shift school students.

The weekdays sleep duration of morning shift and dayshift students in the first year was found to be $6.93 \pm 0.09$ and $8.58 \pm 0.14$ hours respectively, whereas the weekend sleep duration of the two groups was found to be $8.49 \pm$ 0.15 and $9.19 \pm 0.19$ hours respectively. In the second year, morning shift and dayshift students were found to sleep for an average $6.73 \pm 0.10$ and $8.11 \pm 0.14$ hours respectively, in the weekdays and $8.06 \pm 0.14$ and $8.78 \pm$ 0.13 hours in weekends. The morning group was also found to have an earlier wakeup time of 5:23 \pm 00:03 AM 
Salivary Alpha Amylase as Marker of Sleep Deprivation

Table 1: Comparison of sleep variables and sAA activity between morning and dayshift students in ninth class

\begin{tabular}{|c|c|c|c|c|c|}
\hline & \multirow[b]{2}{*}{ Morning shift $(n=79)$} & \multirow[b]{2}{*}{ Dayshift $(n=77)$} & \multicolumn{3}{|c|}{ ANOVA summary } \\
\hline & & & $F$ & $d f$ & $p$ \\
\hline Sleep duration (weekdays) & $6.93 \pm 0.09$ & $8.58 \pm 0.14$ & 98.25 & 1,154 & 0.000 \\
\hline Sleep duration (weekends) & $8.49 \pm 0.15$ & $9.19 \pm 0.19$ & 8.98 & 1,154 & 0.003 \\
\hline Bedtime (weekdays) & $10: 20 \pm 00: 05$ & $10: 11 \pm 00: 08$ & 0.84 & 1,154 & 0.362 \\
\hline Wakeup time (weekdays) & $5: 23 \pm 00: 03$ & $6: 56 \pm 00: 07$ & 136.00 & 1,154 & 0.000 \\
\hline ESS score & $7.08 \pm 0.32$ & $5.86 \pm 0.39$ & 5.83 & 1,154 & 0.017 \\
\hline sAA activity $(\mathrm{U} / \mathrm{mL})$ & $27.76 \pm 1.47$ & $25.46 \pm 1.74$ & 1.017 & 1,166 & 0.315 \\
\hline
\end{tabular}

Table 2: Comparison of sleep variable and sAA activity between morning and dayshift students in tenth class

\begin{tabular}{llllll}
\hline & & & \multicolumn{3}{c}{ ANOVA summary } \\
\cline { 3 - 6 } & Morning shift $(n=71)$ & Dayshift $(n=69)$ & $F$ & $d f$ & 0.138 \\
\hline Sleep duration (weekdays) & $6.73 \pm 0.10$ & $8.11 \pm 0.14$ & 65.34 & 1,138 & 0.000 \\
Sleep duration (weekends) & $8.06 \pm 0.14$ & $8.78 \pm 0.13$ & 13.92 & 1,138 \\
Bedtime (weekdays) & $10: 34 \pm 00: 06$ & $10: 37 \pm 00: 05$ & 0.17 & 1,138 & 0.681 \\
Wakeup time (weekdays) & $05: 18 \pm 00: 04$ & $06: 56 \pm 00: 08$ & 115.80 & 1,138 & 0.000 \\
ESS score & $7.23 \pm 0.31$ & $7.23 \pm 0.46$ & 0.000 & 1,138 & 0.991 \\
sAA activity $(\mathrm{U} / \mathrm{mL})$ & $44.62 \pm 3.93$ & $35.01 \pm 3.39$ & 4.013 & 1,143 & 0.047 \\
\hline
\end{tabular}

Table 3: Comparison of sleep variables and SAA activity among students in ninth and tenth class (irrespective of school timing)

\begin{tabular}{llllll}
\hline & & & \multicolumn{3}{c}{ ANOVA summary } \\
\cline { 3 - 5 } & First year $(n=156)$ & Second year $(n=140)$ & $F$ & \multicolumn{2}{c}{$d f$} \\
\hline Sleep duration (weekdays) & $7.74 \pm 0.11$ & $7.41 \pm 0.10$ & 5.18 & 1,294 & 0.024 \\
Sleep duration (weekends) & $8.84 \pm 0.12$ & $8.43 \pm 0.10$ & 6.675 & 1,294 & 0.010 \\
Bedtime (weekdays) & $10: 16 \pm 00: 04$ & $10: 36 \pm 00: 04$ & 10.303 & 1,294 & 0.001 \\
Wakeup time (weekdays) & $06: 09 \pm 00: 05$ & $06: 07 \pm 00: 06$ & 0.067 & 1,294 & 0.796 \\
ESS score & $6.47 \pm 0.26$ & $7.23 \pm 0.27$ & 4.06 & 1,294 & 0.045 \\
sAA activity $(\mathrm{U} / \mathrm{mL})$ & $26.61 \pm 1.14$ & $36.58 \pm 2.21$ & 17.324 & 1,311 & 0.000 \\
\hline
\end{tabular}

and 05:18 \pm 00:04 AM respectively in the first and second year as compared with the later wakeup time of 6:56 \pm 00:07 AM and 06:56 \pm 00:08 AM observed among the dayshift group in the first and second year respectively.

A significant difference ( $p=0.017$ ) was also observed in sleepiness level in the two groups in the first year of the study but not in the following year. Morning group was found to have a higher level of sleepiness [Epworth Sleepiness Scale (ESS) score of $7.08 \pm 0.32$ and $5.86 \pm 0.39$ respectively, among morning and dayshift students] in the first year. But in the second year, the difference was not found to be significant $(7.23 \pm 0.31$ and $7.23 \pm 0.46$ respectively, among morning and dayshift students).

\section{Analysis of Sleep Behavior of Students in the First and Second Year of the Study irrespective of School Timings}

In the first and second year of study, ANOVA revealed a significant difference in the sleep duration, bedtime, and ESS score of students. Students were found to sleep for significantly less duration in weekdays $(p=0.024)$ as well as weekends $(p=0.010)$ in the second year as compared with that in the previous year. Results also suggest a significant delay in the bedtime $(p=0.001)$ but no significant change in the wakeup time of students was observed (Table 3). Students in the second year were also found to have a significantly higher level of sleepiness $(p=0.045)$.

\section{School Timing and Amylase Activity}

Analysis of data through Statistical Package for the Social Sciences version 16 revealed a heightened association of sAA enzyme activity with sleep durations and sleepiness levels of adolescent students (Graphs 1 and 2). Amylase activity was found to have a significant negative correlation with sleep duration $(\mathrm{r}=-0.129, \mathrm{p}=0.026, \mathrm{n}=296)$, whereas a significant positive correlation of amylase activity was observed with ESS score $(r=0.262, p=0.000$, $n=296$ ). It was also noticed that the level of salivary amylase activity significantly varies with the degree of sleepiness. When level of salivary amylase activity was compared between EDS subjects and non-EDS subjects, amylase activity was found to be significantly higher $\left(\mathrm{F}_{1,294}=9.13, \mathrm{p}=0.003\right)$ among EDS subjects $(\mathrm{n}=61)$ as compared with non-EDS subjects $(n=235)$. The level of amylase activity for EDS and non-EDS subjects was found to be $39.33 \pm 3.51$ and $29.76 \pm 1.33$ respectively (Graph 3 ). 


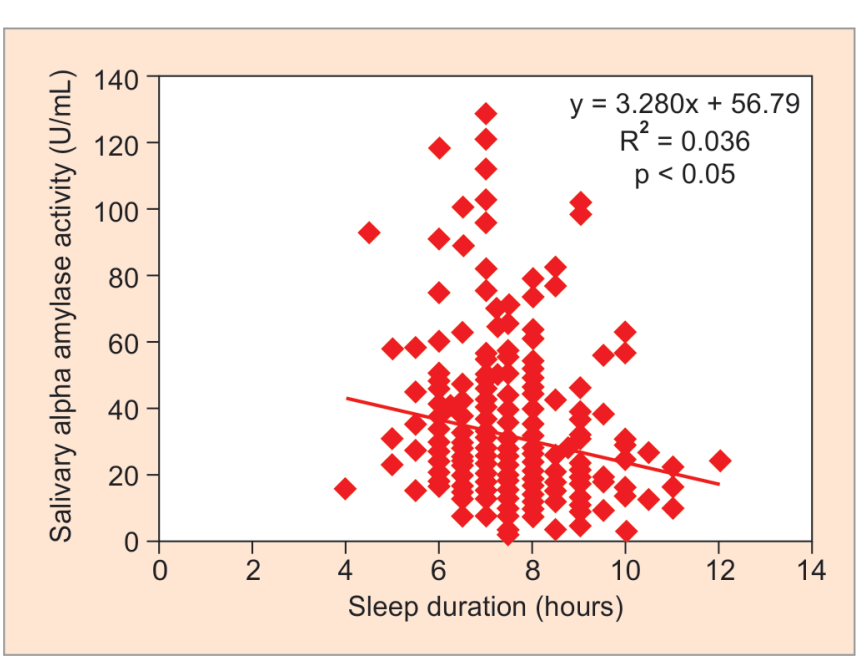

Graph 1: Association between sAA and sleep duration

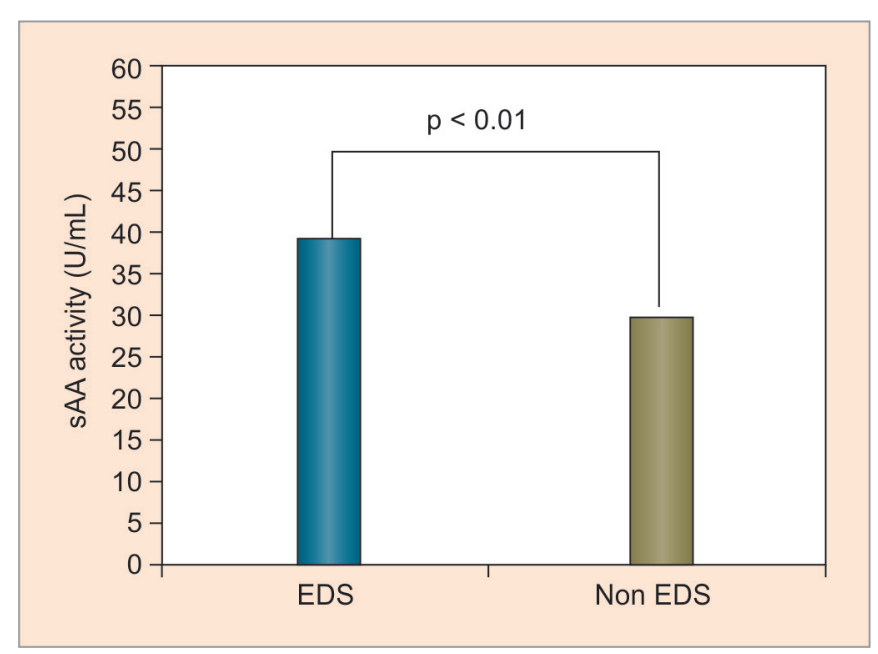

Graph 3: Comparison of amylase activity in EDS and non-EDS subjects

\section{sAA Activity as a Function of School Timing and Progression to Higher Class}

Salivary alpha amylase activity for morning shift students in the ninth and tenth class was found to be $27.76 \pm 1.47$ and $40.75 \pm 3.38 \mathrm{U} / \mathrm{mL}$ respectively, whereas the level of sAA in dayshift students in ninth and tenth class was found to be $25.46 \pm 1.74$ and $31.97 \pm 2.71 \mathrm{U} / \mathrm{mL}$ respectively. As shown in Graph 4, it was revealed through ANOVA that there is a significant difference in sAA levels between morning and dayshift students $\left(\mathrm{F}_{1,143}=4.013\right.$, $\mathrm{p}=0.047)$ in the tenth class but not in the ninth class $\left(\mathrm{F}_{1,166}\right.$ $=1.017, \mathrm{p}=0.315$ ).

When the 2 years data were subjected to paired t-test, it was found that the amylase activity of students has increased with progression to the tenth class (Table 3). Paired sample t-test reveals that the difference between amylase activity among morning group students in the ninth and tenth class is significant $\left(t_{75}=3.61, p=0.001\right)$ and that the average amylase activity recorded in second

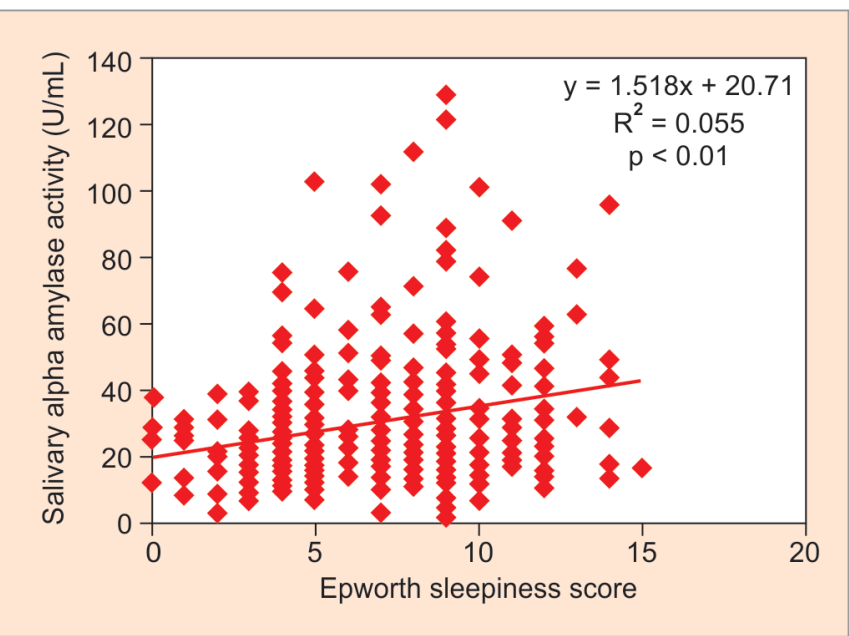

Graph 2: Association between SAA and ESS

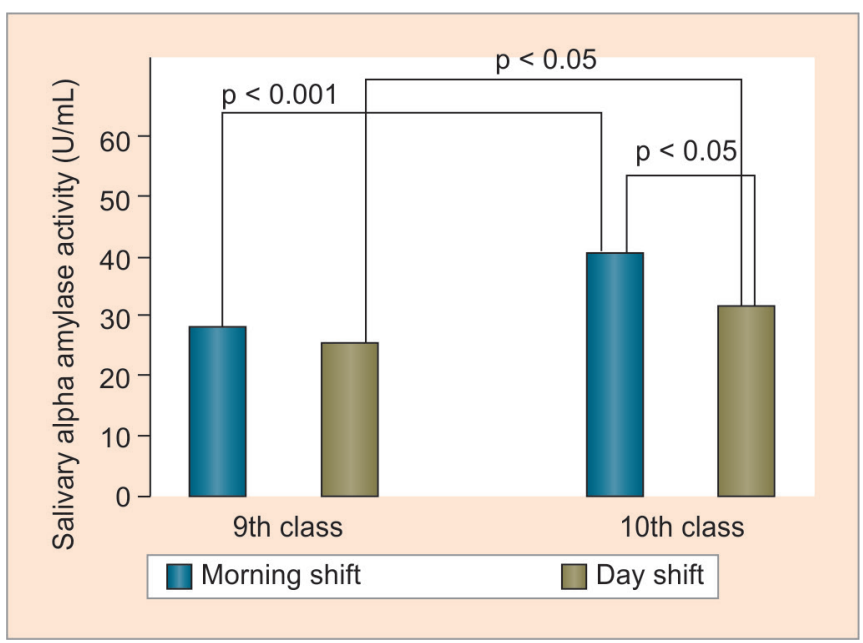

Graph 4: Comparative chart of amylase activity in morning and dayshift students

year (tenth class) is 13.6 times higher than that recorded in the ninth class (95\% confidence interval, CI [21.10, 6.11]). Similarly, among dayshift students it was revealed through paired sample t-test that the difference between amylase activity of students in the ninth and tenth class is significant $\left(\mathrm{t}_{68}=3.061, \mathrm{p}=0.003\right)$ and that the average amylase activity in the tenth class is 9.8 times higher than the average amylase activity observed in ninth class $(95 \%$ CI [16.19, 3.41]).

In the pooled data, the sAA activity was found to be $33.93 \pm 1.85$ and $28.40 \pm 1.57$ respectively, among morning and dayshift students and the difference was found to be significant $\left(\mathrm{F}_{1,311}=5.18, \mathrm{p}=0.024\right)($ Graph 5).

\section{DISCUSSION}

Prevalence of sleepiness among human population is rampant throughout the world. As a result, it has caught the attention of the researchers in the recent past. Besides its widespread prevalence in adults, the school-going 


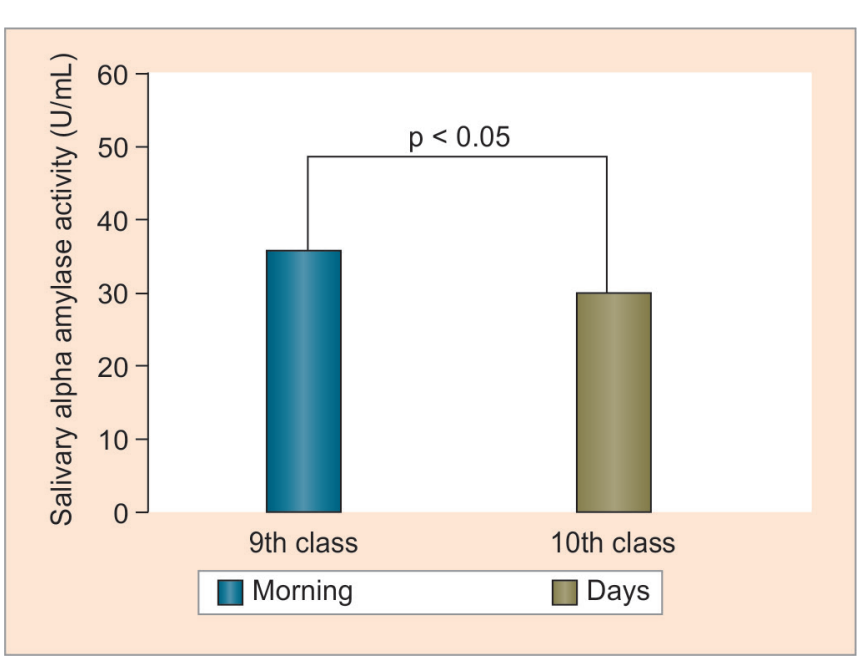

Graph 5: Comparison of sAA activity among students as a function of school timing in the pooled data

adolescents are also not spared of this unwanted social burden. School start timing has been reported to be an important factor in causing sleep deprivation among adolescents leading to deterioration in performance. However, a quantifiable, noninvasive biochemical marker for objective assessment of sleep deprivation is yet to be established. The present study is an attempt to find out utility of enzyme sAA as a biomarker of sleep deprivation among adolescent school-going students in association with the impact of school timings of students. The study also highlights the association of this biomarker with sleep duration of students as they progress toward higher class.

Studies conducted on Drosophila have revealed that the activity of salivary amylase increases along with a concomitant increase of mRNA for encoding this protein following sleep deprivation. ${ }^{7}$ Similar increase in salivary amylase mRNA and level of amylase enzyme activity has also been observed in human after extended waking. ${ }^{6}$ Hence, both these biochemical variables have been suggested as biomarkers for sleep deprivation in humans. However, this observation was based on a very limited number $(<10)$ of subjects and barring this lone study, report at population level is completely lacking and the validation at population level is most warranted. The present study was undertaken to examine the use of salivary amylase enzyme as a biomarker of sleep deprivation in large human population followed up for a period of 2 years. Analysis of data revealed that sAA activity (irrespective of school timings) was found to have a significant negative association with sleep duration. Amylase activity was also found to have a significant positive correlation with ESS score, suggesting that the level of sAA activity is a potent indicator of degree of sleepiness. An increased amylase level in saliva among the students suffering from EDS is a further confirmatory evidence for the association between sAA activity and sleepiness level.
Sleep behavior of students as a function of school timings was found to vary significantly. The findings of the study illustrate a significantly reduced sleep duration in the morning group than that of the day group in the first as well as second year of the study. From the data, it follows that earlier school timings contribute significantly toward the reduction in sleep duration of adolescents. The present results corroborate with our earlier findings where we have reported sleep deprivation among morning shift school students due to earlier school timings and have recommended delaying the school timing by 1 or 2 hours. ${ }^{18}$ It was also revealed that the sleep duration (weekdays) of students, irrespective of their school start timings, has reduced in the second year. Reduction in sleep of these students in the second year irrespective of the school start timings may be due to their more academic demand in higher class. When the enzyme activity was compared as a function of school timings, amylase activity was found to be significantly higher among the morning group as compared with the dayshift group in the second year of the study. A significantly higher salivary amylase activity among morning school students in the second year may be attributable to their sleep deprivation. Further, this notable reduction in sleep duration can be explained by the significant delay in the bedtime with advanced grade but a constant wakeup time of students throughout the study. Thus, it also follows from the findings that school students as they progress toward higher grade exhibit reduced sleep duration due to higher amount of time required to meet academic demands in the late night hours.

The present report, to the best of our knowledge, highlights the importance of sAA in the assessment of sleepiness level for the first time in a large population studied on longitudinal basis. The data underscore the usefulness of enzyme sAA in the evaluation of sleep deprivation among the adolescent population. The findings of this study clearly indicate that measurement of salivary amylase activity may be a suitable noninvasive biochemical parameter for objective assessment of sleep deprivation among individual as well as at population level.

\section{ACKNOWLEDGMENTS}

Authors are grateful to the school authorities and student participants for their kind cooperation. They would also like to thank the Chhattisgarh Council of Science and Technology (CGCOST), Raipur, India, for their financial support and Head, School of Life Sciences, Pt. Ravishankar Shukla University, Raipur, India, for providing facilities to carry out this work. 


\section{REFERENCES}

1. Chourasia A, Sinha N, Pradhan RK. A study on salivary $\alpha$-amylase activity as a marker of stress. Biochem Cell Arch 2016;16(2):373-377.

2. Rohleder N, Nater UM, Wolf JM, Ehlert U, Kirschbaum C. Psychosocial stress-induced activation of salivary alphaamylase: an indicator of sympathetic activity? Ann NY Acad Sci 2004 Dec;1032(1):258-263.

3. Wagner J, Cik M, Marth E, Santner BI, Gallasch E, Lackner A, Raggam RB. Feasibility of testing three salivary stress biomarkers in relation to naturalistic traffic noise exposure. Int J Hyg Envir Heal 2010 Mar;213(2):153-155.

4. Spiegel K, Leproult R, Van Cauter E. Impact of sleep debt on metabolic and endocrine function. Lancet 1999 Oct;354(9188):1435-1439.

5. Park CS, Guilleminault C, Park HJ, Cho JH, Lee HK, Son HL, Hwang SH. Correlation of salivary alpha amylase level and adenotonsillar hypertrophy with sleep disordered breathing in pediatric subjects. J Clin Sleep Med 2014 May;10(5): 559-566.

6. Seugnet L, Boero J, Gottschalk L, Duntley SP, Shaw PJ. Identification of a biomarker for sleep drive in flies and humans. Proc Natl Acad Sci USA 2006 Dec;103(52):19913-19918.

7. Thimgan MS, Duntley SP, Shaw PJ. Changes in gene expression with sleep. J Clin Sleep Med 2011 Oct;7(Suppl 5): S26-S27.

8. Mercer PW, Merritt SL, Cowell JM. Differences in reported sleep need among adolescents. J Adolescent Health 1998 Nov;23(5):259-263.
9. Nixon GM, Thompson JM, Han DY, Becroft DM, Clark PM, Robinson E, Waldie KE, Wild CJ, Black PN, Mitchell EA. Short sleep duration in middle childhood: risk factors and consequences. Sleep 2008 Jan;31(1):71-78.

10. Carskadon MA, Harvey K, Duke P, Anders TF, Litt IF, Dement WC. Pubertal changes in daytime sleepiness. Sleep 1980;2(4):453-460.

11. Beebe DW, Rose D, Amin R. Attention, learning, and arousal of experimentally sleep-restricted adolescents in a simulated classroom. J Adolescent Health 2010 Nov;47(5):523-525.

12. Millman RP. Excessive sleepiness in adolescents and young adults: causes, consequences, and treatment strategies. Pediatrics 2005 Jun;115(6):1774-1786.

13. Owens JA, Belon K, Moss P. Impact of delaying school start time on adolescent sleep, mood, and behavior. Arch Pediatr Adol Med 2010 Jul;164(7):608-614.

14. Danner F, Phillips B. Adolescent sleep, school start times, and teen motor vehicle crashes. J Clin Sleep Med 2008 Dec;4(6): 533-535.

15. Nag C, Pradhan RK. Sleep deprivation and level of C-reactive protein. Biol Rhythm Res 2011 Jun;42(3):209-218.

16. Stern AL, Naidoo N. Wake-active neurons across aging and neurodegeneration: a potential role for sleep disturbances in promoting disease. Springer Plus 2015 Jan;4(1):25.

17. Abbott SM, Videnovic A. Chronic sleep disturbance and neural injury: links to neurodegenerative disease. Nat Sci Sleep 2016 Jan;8:55-61.

18. Pradhan RK, Sinha N. Impact of commuting distance and school timing on sleep of school students. Sleep Biol Rhythms 2017 Feb;15(2):153-158. 